\section{A. ARS BILDUMA ISSN 1989-9262 UPV/EHU Press} ARSBILDUMA (CC BY-NC-ND 4.0)

https://doi.org/10.1387/ars-bilduma.21615 BIBLID [(2021), 11;33-47]

Recibido: 28/03/2020 Aceptado: 30/06/2020

\section{IÑIGO SARRIUGARTE GÓMEZ}

Universidad del País Vasco (UPV/EHU)

Facultad de Letras

Paseo de las universidades, 5

01006 Vitoria-Gasteiz (Álava)

inigo.sarriugarte@ehu.eus

http://orcid.org/0000-0003-0206-9864

\title{
EL PROYECTO HOLÍSTICO DE EMMA KUNZ: CUANDO EL ARTE SE CONVIERTE EN ALGO MÁS
}

\author{
THE HOLISTIC PROJECT OF EMMA KUNZ: WHEN ART BECOMES SOMETHING \\ ELSE
} LE PROJET HOLISTIQUE D'EMMA KUNZ: QUAND L'ART DEVIENT QUELQUE
CHOSE DE PLUS

\section{RESUMEN}

La artista suiza Emma Kunz (1892-1963) desarrolló una nutrida producción de patrones energéticos, que asumían una cercanía visual y simbólica con yantras y mandalas. Aunque no se han encontrado datos fehacientes al respecto, de acuerdo a la bibliografía consultada, así como las aportaciones realizadas por el propio museo de la creadora, se cree que llegó a manejar la literatura alquímica de Paracelso y textos cristianos, así como fuentes escritas de escuelas herméticas. La gran mayoría de sus gráficos se elaboraron con objetivos terapéuticos, en la creencia de que emitían una onda de forma que podía afectar al paciente o espectador cuando se contemplaban.

PALABRAS CLAVE

Emma Kunz; radiestesia; curación; dibujo; abstracción.

\section{ABSTRACT}

The Swiss artist Emma Kunz (18921963) developed a rich production of energetic patterns, which assumed a visual and symbolic proximity to yantras and mandalas. Although no reliable dat have been found in this regard, according to the bibliography consulted, as well as the contributions made by the creator's own museum, it is believed that she read the alchemical literature of Paracelsu and Christian texts, as well as written sources of hermetic schools. The majority of her graphics was made for therapeutic purposes, in the belief that they emitted a wave form in a way that could affect the patient or viewer when they were viewed.

KEYWORDS

Emma Kunz; Radiesthesy; Healing; Drawing; Abstraction.
RÉSUMÉ

L'artiste suisse Emma Kunz (1892-1963) a développé une production de motif énergétiques, qui supposait une proximité visuelle et symbolique avec les yantras et les mandalas. Bien qu'aucune donnée fiable n'ait été trouvée à cet égard, selon la bibliographie consultée, ainsi que les contributions apportées par le propre musée de la créatrice, on pense qu'elle a lu la littérature alchimique de Paracelse et les textes chrétiens, ainsi que les sources écrites d'écoles hermétiques. La majorité de ses graphiques ont été réalisés à des fins thérapeutiques, dans la conviction qu'ils émettaient une onde de forme qui pourrait affecter le patient ou le spectateur lorsqu'ils étaient visionnés.

\section{MOTS-CLÉS}

Emma Kunz, radiesthésie, guérison, dessin, abstraction. 


\section{BREVE RESEÑA BIOGRÁFICA}

Emma Kunz nace en Brittnau (Suiza) en 1892 en el seno de una familia de tejedores. A la edad de 18 años, comenzó a mostrar capacidades telepáticas, sanadoras y a desarrollar una práctica radiestésica ${ }^{1}$ mediante el uso del péndulo, muy posiblemente también acompañado de la imposición de manos como terapia curativa.

Su interés por el arte no se hizo esperar, ya que pudo comprobar que tanto la estructuración lineal como cromática eran soportes con capacidades para influir en el espectador. Aunque vivió la mayor parte de su vida con su familia, entre 1923 y 1939, comenzó a trabajar durante los veranos como ama de llaves para la familia del pintor y crítico de arte Jakob Friedrich Welti (1871-1952), convirtiéndose en una inestimable compañera de debate para el artista.

En 1938 comienza su investigación con los dibujos de gran formato, es decir, gráficos de composiciones complejas relacionados con la exploración y aplicación de patrones energéticos. Estos métodos tan poco ortodoxos para la época obligaron a la artista a no difundir en exceso su obra, únicamente conocida entre su círculo más íntimo de amistades y obviamente entre sus pacientes. Entre ellos, Anton Meier, quien había sido curado de la poliomielitis. Éste recopilará y documentará todos sus trabajos artísticos, fundando en 1986, junto a las canteras romanas de Würenlos, cerca de Zürich, el Centro Emma Kunz. Su deseo fue, no sólo crear un espacio artístico, sino de proyección curativa, por este motivo, se sitúa al lado de dicha cantera, de donde la artista extraía un tipo de roca con propiedades terapéuticas. El museo se inaugurará posteriormente, en 1991, con una exposición permanente que comprende alrededor de 70 de sus obras más relevantes.

1. De acuerdo a Héctor V Morel la radiestesia podría ser definida de la siguiente manera. “Técnica de captación de las ondas emitidas por todos los cuerpos, en la que se producen fenómenos fisio-psicológicos, mediante el empleo de instrumentos adecuados (péndulo o varilla) que generan respuestas conven cionales cuya interpretación permite al operador determinar la ubicación, naturaleza, composición propiedades de los cuerpos". Para obtener más información al respecto, ver MOREL, H. V.: Radiestesia Cuestionario integral. Buenos Aires, Kier Editorial, 2005, pp. 12-13. Como sinónimos de este término, también se pueden emplear la rabdomancia y el zahorismo.

Según Emma Kunz, estas aptitudes radiestésicas podían ser desarrolladas mediante prácticas y ejercicios, que estaban al alcance de todos, por este motivo, rechazaba el término milagro, ya que se trata cicios, que estabn a alca a de de activar una serie de habilidades que permanecen inactivas en cada person. Rensa HOFMANN, V.: «Superwoman Emma Kunz. Aspekte aus John Grays Buch Wir werden wie Gott sein als Basis fü eine Betrachtung des Lebenswerkes von Emma Kunz», sección 2. http://verahofmann.de/sandberg/ CM3_writing_VH.pdf (Consultado el 24/03/2020).
Asumió el nombre artístico de Penta, apelativo abreviado de pentagrama ${ }^{2}$, la estrella de cinco puntas, que en la antigüedad representaba a Venus. Igualmente, Pitágoras lo aplicó como símbolo de la salud y vitalidad, siendo este otro de los motivos a la hora de seleccionar dicha denominación, junto con su interés por la configuración matemática.

En 1930 aparece su libro de poemas La vida. Más adelante, en 1953 escribe dos libros sobre el arte de dibujar: El Milagro de la Revelación Creativa y Nuevo Método de Dibujar, conteniendo ambos el mismo subtítulo: Diseño y forma como medida, ritmo, símbolo y transformación del número y el principio.

En 1941 descubre el poder energético y curativo de la arenisca en la cantera de Würenlos a la que llamó $A I O N A^{3}$. Sería en esta antigua cantera romana, donde pudo detectar mediante mediciones radiestésicas el potencial energético del lugar, proveniente del interior de la Tierra. La zona cero de este lugar se ubica en la poderosa gruta en el centro de dicho espacio. Comenzó a extraer esta roca sedimentaria de la zona, que era pulverizada y molida en una fina mezcla, que sería empleada para sus tratamientos terapéuticos. Para Emma Kunz, el interés de este material no sólo residía en su composición mineral especial, sino sobre todo en sus propiedades energéticas ${ }^{4}$. Emma Kunz dejó anotaciones del valor curativo de dicha roca, afirmando que "el poder universal de AION A debe hacerse accesible para la humanidad". Por otro lado, gracias a su hermana mayor, Hulda, que era enfermera diaconal, también pudo introducirse y ahondar en los conceptos básicos de la fitoterapia ${ }^{6}$, recetando plantas que ella misma cultivaba en su jardín.

2 Este símbolo místico puede formarse dibujándolo con una línea sencilla y continúa, siendo este mismo proceder

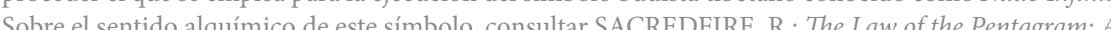
Sobre Alchemist Handbook for Magic and Divination Using the Application of Spiritual Codes and the Law of Atraction. New York, 22 lions, 2016; BLASCHKE, J.: Enciclopedia de los símbolos esotéricos. Barcelona, Robinbook, 2001, p. 206.

3 El término AION A proviene del griego y dispone de varias acepciones, entre las que se encuentran ilimitado y eternidad. Para un estudio filosófico y etimológico de carácter más detenido, consultar KEIZER, H.M.: Life Time Entirety. A Study of AION in Greek Literature and Philosophy, the Septuagint and Philo. Zoetermeer, Holland, Academish Proefschrift, 2010; JUNG, C. G.: Aion: Researches Into the Phenomenology of the Self. New York, Princeton University Press, 1968.

4 El polvo de roca suizo AION A está catalogado como dispositivo médico de categoría I, aprobado en 1984 por el organismo público Swissmedic - Agencia Suiza para Productos Terapéuticos. De hecho, se ha probado su efecto curativo especialmente en casos inflamatorios y otras patologías médicas. En la actualidad, este producto puede ser comprado en las farmacias de este país. 
En 1951 se muda esta vez a Waldstatt, en el cantón de Appenzell, donde residía un importante grupo de médicos alternativos y holísticos, lo que le permitió practicar libremente sus artes curativas, conociendo al químico Franz Decurtins, un entusiasta partidario de su procedimiento sanador, que le ayudará a producir medicinas en su laboratorio de acuerdo a las instrucciones de la propia investigadora.

Cuando fallece en 1963 su producción comprendía cientos de dibujos coloreados, la gran mayoría de gran formato. De hecho, en memoria de esta creadora, se crea en 2008 una ruta de senderismo que parte de Waldstatt, lo que posibilita recorrer los principales lugares relacionados con la vida de Emma Kunz. Igualmente, la oficina estatal de correos de Suiza en 1993 le dedicó un sello, a modo de reconocimiento por su labor como artista, investigadora y sanadora.

Desde 1973, su obra es solicitada para la conformación de numerosas colectivas, y retrospectivas, como las celebradas en el Städtische Kunsthalle de Düsseldorf y el Museo de Arte Moderno de París, ambas en 1976. Entre las principales colectivas, destacamos Suiza Visionaria (1992), en el Museo Nacional Reina Sofía; la Biennale Lyon (1999), comisariada por Harald Szeemann; Richtkräfte für das 21. Jahrhundert (1999), en el Kunsthaus Zurich, dedicada a Emma Kunz, Joseph Beuys y Rudolf Steiner. Igualmente, su obra ha sido expuesta en el Drawing Centre New York (2005); Santa Monica Museum of Art (2005); The Irish Museum of Modern Art, Dublin (2006); Hypnos. Images et inconscients en Europe 1900-1949, en Métropole Musée d'art moderne, Lille (2009), donde se aborda la influencia del psicoanálisis, el mediumnismo, el espiritismo y otro tipo de prácticas similares, que fueron aplicadas por distintos creadores; así como Cartografías contemporáneas. Dibujando el pensamiento, en la Fundación La Caixa de Barcelona y Madrid (2012-2013). Este último año, también aparece representada en la 55 Bienal de Venecia, lo que demuestra la aceptación de la figura de Emma Kunz como una de las pioneras de la abstracción europea.

KUNZ, Emma: "Emma Kunz. Artist, Researcher, Healer". https://www.emma-kunz.com (Consultado el 24/03/2020).

6 Esta creadora es considerada una de las curanderas más importantes de Europa de los últimos tiempos, lo que le valió algunos de los siguientes apelativos: visionaria entre los ciegos y la santa del pueblo, entre otros. Sobre estas denominaciones y otras consideraciones holísticas relacionadas, revisa MUSCIONICO, D.: Starke Schweizer Frauen. Zürich, Limmat Verlag, 2011, pp. 42-47.

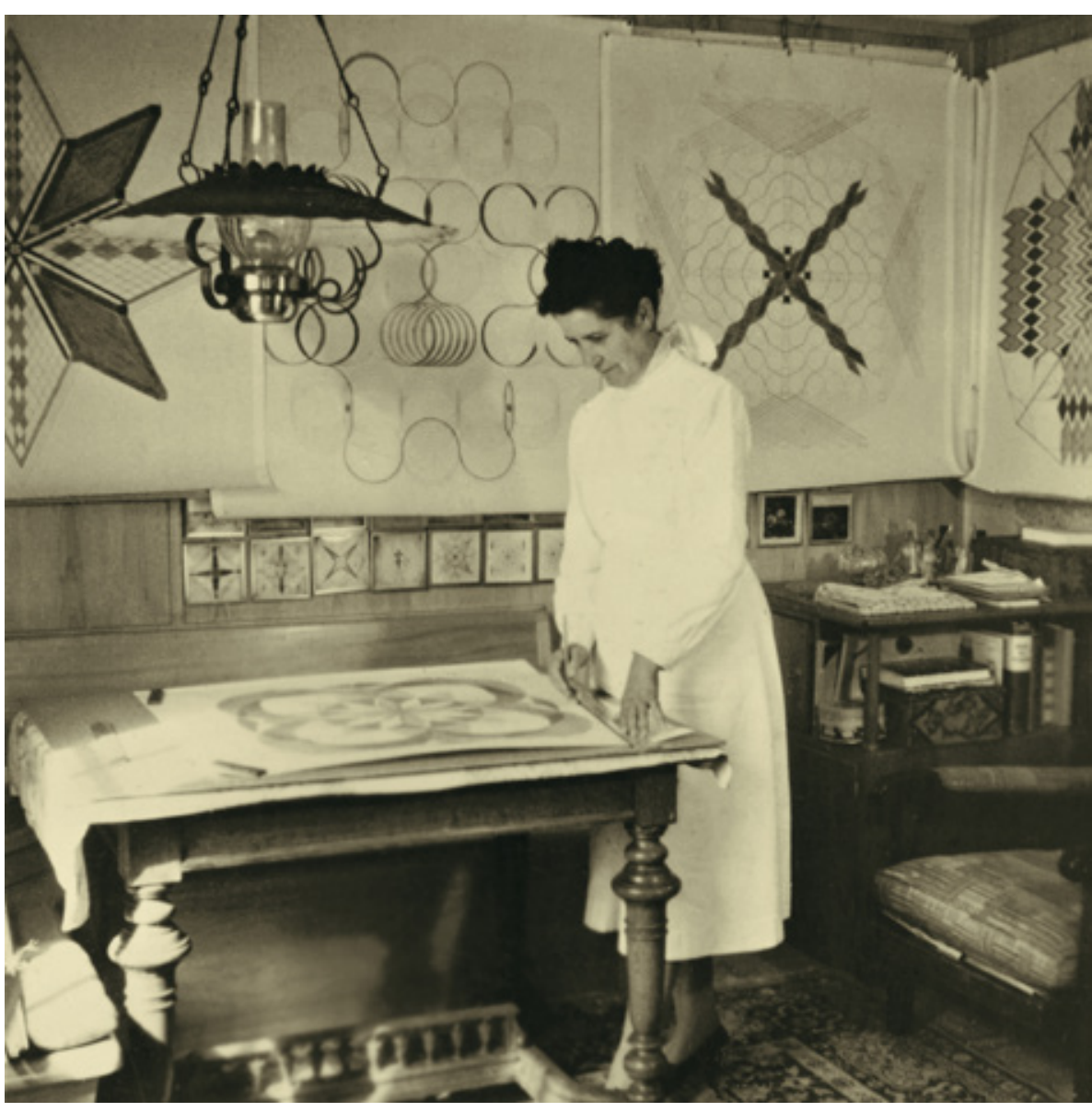

Fig. 1: Emma Kunz trabajando en su taller, Waldstatt, 1958. Emma Kunz Zentrum 


\section{PRINCIPALES FUENTES CREATIVAS DE LA ARTISTA}

El arte moderno en Suiza venía marcado especialmente por la presencia del constructivismo y las tendencias concretas. Sin tener una relación con estos postulados y buscando su propio camino, Emma Kunz empleó el péndulo para obtener estructuras compositivas, que representaban campos y patrones energéticos. Esta condición de ejecución inusual no impide que su obra asuma un parentesco formal con ciertas prácticas constructivistas, por ejemplo, con los últimos trabajos de Auguste Herbin (1882-1960), quien desarrolló conexiones entre palabras, números, colores, formas y tonos en visiones geométricas; o con los trabajos de Alfred Jensen (1903-1981), al producir formulaciones de relaciones numéricas entre pirámides y cuerpos celestiales.

\section{Como afirma Hendel Teicher:}

"Hay muchos paralelismos entre Kunz y Max Bill (1908-1994), la fuerza conductora por detrás del Arte Concreto Suizo (...) Como Kunz, Bill hizo trabajos a través de un proceso de resolución de problemas. En sus diversas actividades, ambos crearon formas simples y elementales sin jerarquías constructivas de valor. Para ambos, el arte era la expresión de una búsqueda - una búsqueda de leyes análogas al razonamiento matemático. Alcanzaron la unidad a través de la estructura geométrica y la precisión de su trabajo puede invocar ingeniería y diagramas mecánicos. Además, para ambos artistas, la pintura era en si misma una máquina que funcionaba instrumentalmente sobre el espectador, produciendo un efecto. Verdaderamente, su trabajo puede ser visto como una parte de la estética que formaba el diseño industrial moderno de Suiza" ${ }^{\text {" }}$.

Aunque anotemos ciertos parentescos y acercamientos formales, Emma Kunz no se relacionó con ninguna corriente de arte contemporáneo de su país, ni siquiera con otros artistas $^{8}$, a excepción de Jakob Friedrich Welti. De hecho, el movimiento más relevante

7 TEICHER, H.: "Kaleidoscopic Visions", en De ZEGHER, C. \& TEICHER, H. (eds.): 3 x Abstraction. New methods of drawing. Hilma Af Klint, Emma Kunz, Agnes Martin. New York, The Drawing Center, Yale University Press, 2005, p. 137

8 El 17 de octubre de 2018 se remite un email al Emma Kunz Zentrum con la intención de ponernos en contacto con algún responsable del centro y aclarar una serie de dudas, así como obtener nueva información sobre los procedimientos y fuentes de referencia consultadas por la artista. La sección de Secretaría del museo - Sekretariat accede a contestar un cuestionario (con la condición de no publicar el nombre del responsable de dicho departamento), que es remitido el citado día, enviándonos posteriormente po en los años 50 era el Zurich Concrete, una de las ramas del Arte Concreto, que solo logró un efecto generalizado a finales de dicha década y Emma Kunz ya estaba allí antes de esta fecha realizando sus trabajos abstractos. En definitiva, prefirió mantenerse distante de las principales tendencias artísticas y estéticas de la época, lo que le facilitó producir una obra con un carácter original e inédito tanto en resultados como en procesos de ejecución original; posicionamiento metodológico, que le llevó a ser comparada con otras artistas de creación divergente, como Georgiana Houghton (1814-1884), Hilma af Klint (1862-1944) Jeanne Natalie Wintsch (1871-1944) y Olga Fröbe-Kapteyn (1881-1962), entre otras.

El propio Harald Szeemann se preguntaba si el trabajo de Kunz alguna vez se podría llamar arte en el sentido más estricto ${ }^{9}$, de hecho, ella no se veía a sí misma como artista, sino principalmente como una investigadora de fuerzas sutiles aplicadas a la resolución de problemas mediante medios artísticos, siendo denominado su trabajo creativo por ella misma como investigación ${ }^{10}$, proceder que no ha sido considerado como un rechazo hacia el arte, ya que actualmente su obra se expone en distintos certámenes y centros de reconocido prestigio internacional. Lo que resulta evidente es que sus trabajos nunca procedían del l'art pour l'art, ya que se materializan en base a un objetivo superior que transcendía la mera delectación estética.

Sí es cierto que su experimentación iba en correlación con otras tantas investigaciones que se habían desarrollado dentro del arte moderno y que se correspondían con el espiritismo, la cosmología y la búsqueda representativa de estados superiores de conciencia, impulsados entre otros gracias a los descubrimientos de los rayos X, la teoría de la relatividad y los primeros pasos de la física cuántica. Lo que realmente le diferencia de otros artistas es su investigación en los entresijos de una dimensión más sutil y no tan física, lo que conlleva una metodología más compleja y de carácter inédito, convirtiéndose su capacidad intuitiva en el verdadero motor de creación, a diferencia por ejemplo de la práctica espiritista de Hilma af Klint.

email sus comentarios el 26 de octubre. En sus respuestas, nos transcriben que a los expertos, que ha investigado la obra de Emma Kunz, no les consta que la artista mostrara interés por la obra de otros creadores. Por lo tanto, no existe información al respecto que se haya podido cortejar y aplicar para una investigación académica.

9 Harald Szeemann, en CHON, D. \& PHILIPS, G. \& RIGOLO, P. (eds.): Harald Szeemann: Selected Writing. Los Angeles, Getty Research Institute, 2018, p. 56.

10 ZWEZ, A.: “...Provided They Know How to Handle Numbers", en VV.AA.: Emma Kunz: Artist, Resear cher, Natural Healer. Würenlos, Emma Kunz Zentrum, 1998, p. 94. 
Por otro lado, es lícito anotar que sus propuestas llegan a mostrar un acercamiento formal y estructural con los tratados renacentistas de Serlio (1537) y Rivius (1575), los diagramas geométricos de Villard de Honnecourt, las variaciones numéricas de Eugène Viollet-leDuc, así como algunos de los dibujos de Oskar Schlemmer. Igualmente, se pueden tejer relaciones visuales con los diseños geométricos persas y los diagramas de las matemáticas árabes, especialmente con el trabajo de Ibn Haitham; así como conparativas con las estructuras de los yantras y mandalas orientales; e incluso los gráficos existentes en el manual Silpa Prakasa ${ }^{11}$, empleado en la escuela tántrica para proyectos arquitectónicos. En todos los anteriores referentes, se asume el fundamento numérico como valor operativo y resolutivo. Igualmente, para Emma Kunz resultaba imprescindible entender y manejar este código para articular tanto compositiva como simbólicamente el dibujo proyectado, y de esta manera reforzar su efectividad curativa. De hecho, las oscilaciones pendulares, que desarrolla la artista para la ejecución de sus obras, no sólo se basan en patrones numéricos, sino también en la manifestación de campos de energía, siendo denominados como "fuerzas de la imagen de la naturaleza"12, en base a un sentido paracélsico, cuyo trabajo conocía por analogía ${ }^{13}$, de ahí, la cercanía argumental con determinados escritos del principal alquimista suizo:

"De esta manera resulta que el hombre es su propio médico, ya que a poco que ayude (opitulatur) a la Naturaleza, ésta transforma su anatomía en un jardín, con la mejor asistencia imaginable. Si estudiamos y escrutamos bien las causas de todas las cosas, vemos que nuestra naturaleza es nuestro mejor médico, ya que posee en sí todo cuanto podemos necesitar"14.

Emma Kunz aporta un sentido artesanal a todo su trabajo al producir modelos y patrones geométricos que se asemejan formal y estructuralmente a composiciones empleadas en el arte popular, en base al uso del papel cuadriculado, que funciona como espacio de medición para la elaboración de telas de bordados, generando un acercamiento fabril y simbólico a este ámbito creativo.

11 Para obtener más información al respecto, remitirse a BHATTARAKA, R. M. K.: Silpa Prakasa: Medieval Orissan Sanskrit Text on Temple Architecture. New Delhi, Motilal Banarsidass, 2005.

12 Emma Kunz, en ZWEZ, A.: op. cit. 96.

13 Ibidem.

14 PARACELSO: Obras Completas (Opera Omnia). Traducción, estudio preliminar y anotaciones de Estanislao Lluesma-Uranga, Sevilla, Renacimiento, 1992, p. 211
A pesar de que no constan datos al respecto ${ }^{15}$, se observa una similitud con los procedimientos de Hans Jenny (1904-1973), un médico suizo que vivió y trabajó en Dornach, interesado en la filosofía, el arte y la música. Su investigación científica estaba casi enteramente dedicada al estudio de los fenómenos invisibles, lo que le indujo a explorar una amplia diversidad de aspectos vitales en relación con las ondas de forma ${ }^{16}$, etiquetando su disciplina con el nombre de cymatics $^{17}$, proveniente de la raíz griega kyma, que significa onda. Su estudio estaba centrado en representaciones de vibraciones o patrones energéticos, que se mostraban mediante estructuras abstractas. De este modo, se observa una cercanía entre ambos, en base a la implicación y orientación de sus investigaciones.

Emma Kunz dejó un legado de más de cuatrocientas composiciones geométricas, sin comentario alguno, excepto en dos propuestas que llevan el título Filosofía de la Vida y Pareja de humanos en el Cosmos (1940), clasificadas respectivamente con los números 012 y $086^{18}$, donde es trazada la evolución energética del hombre del siglo XXI. En este trabajo, se pueden observar numerosos arquetipos: cruces templarias, estrellas de David, ángulos de $60^{\circ}$, etc. A pesar de esta falta de información teórica o interpretativa, sus trabajos siguen influyendo a numerosos creadores, como Louise Despont, mediante sus geometrías, ritmos y mediciones exhaustivas y colores simbólicos; así como en los trabajos de Thomas Hirschhorn, caso de su instalación Superficial Engagement (2006), donde hace uso intensivo de los dibujos geométricos de Emma Kunz, los cuales parecen composiciones que anteceden las actuales obras realizadas por ordenador, etc.

Aunque la artista suiza disponía de un microscopio que solía emplear para obtener datos formales y estructurales de distintos minerales, su principal búsqueda procede evidentemente de una intuición muy afinada y evolucionada, que le permitía producir propuestas con

15 SEKRETARIAT - EMMA KUNZ ZENTRUM: 26/11/2018.

16 En el campo de la radiestesia, este término hace referencia a la vibración energética que parte de la forma de las cosas, es decir, la huella energética (microvibraciones) que emite un objeto, color o cualquier tipo de estructura en un entorno, siendo su impacto y alcance vibratorio de diferente intensidad, por ejemplo, se consideran que las composiciones geométricas generan un mayor potencial. Esta onda de forma es una portadora de información relacionada con la intencionalidad de su construcción. Para obtener mas información al respecto, examinar BELIZAL, A. \& CHAUMERY, L.: Essai de radiesthésie vibratoire, Paris, Editions Desforges, 1976, pp. 105-121. Para una explicación más abreviada, remitirse a OLAZABAI L. Péndulos egipcios. Equilibrio activo con el tallo verde. Almerí Editorial SoldeSol 2019, pp. 108-112.

17 Sobre esta temática, con mena and Vibration. New Hampshire, Macromedia, 2001.

18 Estos dos trabajos son explicados en MEIER, A. C.: "Emma Kunz. Life and Work", en VV.AA.: op. cit. pp. 30-36 
un carácter muy original, lo que no ha impedido que se genere un discurso comparativo entre sus dibujos y "el ámbito molecular, la investigación en cristal de agua y la biología hereditaria, y los ciclos planetarios"19. Como bien afirma Hendel Teicher: "Kunz creó un inventario de patrones únicos que funciona como un atlas o gráfico de referencia..." ${ }^{20}$, ya que era capaz de crear dibujos estructurales de complejas composiciones en base a puntos y sistemas ordenados, que eran distribuidos en el plano. Una vez realizada la pregunta mental, y basándose en el movimiento pendular, ella sabía exactamente donde tenía que establecer los puntos, las líneas y cuales debían mostrar más peso visual, junto con el sentido de los colores y sombreados. Cada elemento siempre tenía su significado y sentido concreto.

Se sabe muy poco de la literatura que manejaba, de hecho, en su casa sólo se encontró en el momento de su fallecimiento el libro titulado Nuestras plantas medicinales ${ }^{21}$. Es posible que hubiera manejado bibliografía relacionada con escuelas del pensamiento ocultista, caso de la antroposofía, y especialmente textos de Paracelso, aunque todas estas posibilidades se asoman con numerosas dudas. Tal y como relata Harald Szeemann: "Se dice que ella nunca leyó a Rudolf Steiner, aunque su meditación rosacruciana para la purificación de las pasiones y los instintos podía haber sido un prototipo de sus mandalas. Ni visitó su sede principal en Dornach, aunque Charlotte Gugelmann ${ }^{22}$ fue allí con el objetivo de buscar información. Emma Kunz mantuvo una distancia con la antroposofía, probablemente debido a su explícito mensaje moral y su organización comunal, que demandaba más de lo que ella - con su vida solitaria, su renuncia al matrimonio, disciplinas y sociedad - estaba preparada para dar"23.

Asimismo, se conoce que el pensador y filósofo Sri Aurobindo ${ }^{24}$ envío tres delegaciones a Brittnau con la intención de convencer a la artista para que fuera a India, y de este modo enriquecer el entorno espiritual de su áshram con su pensamiento europeo, pero Emma Kunz declinó su oferta, alegando que no compartía una actividad misionera, siendo Suiza, donde se debía desarrollar su vocación y habilidades, de hecho, ella expresará que "todo está en la ley de la naturaleza y cada ser humano debe actuar donde vive"25.

9 HOFMANN, V.: op. cit. sección 3 .

20 TEICHER, H.: op. cit., p. 132 .

21 MEIER, A. C.: op. cit., p. 25. Este dato es corroborado por SEKRETARIAT: op. cit

22 Amiga íntima de la artista, con la que comparte desde 1930 determinadas prácticas radiestésicas, como la búsqueda de aguas subterráneas, puntos de radiación terrestre, etc.

23 SZEEMANN, H.: "More than Art: Tiend into Primal Mud and Mystic Light", en VV.AA.: op. cit, p. 70

24 MEIER, A. C.: op. cit. 25; KRUMM, R.: Bewusst weiter gehen: Vom persönlichen zum ganzheitlichen Weltbild, Norderstedt. BoD - Books on Demand, 2018, pp. 18-19.

25 Emma Kunz, en SEKRETARIAT: op. cit.
Nuevamente y sin datos al respecto, y asumiendo como una simple suposición en base a sus profundos conocimientos de numerología, lo lógico hubiera sido que manejara literatura alquimista, así como fuentes provenientes del cristianismo esotérico, el hinduismo y el budismo, incluyendo escuelas herméticas europeas, donde se daban cabida las experiencias clarividentes de Emmanuel Swedenborg, la teosofía, el rosacrucismo y por supuesto las últimas aportaciones de la antroposofía de Rudolf Steiner ${ }^{26}$. Por ejemplo, los dibujos número 004 y 005 (fig. 2 y 3) parecen derivar de gráficos realizados ya por otros alquimistas. Debemos recordar que la simbología alquímica se sustenta en la transformación de formulaciones matemáticas en signos geométricos que acuñaban el apelativo de sellos. Las variaciones formales y compositivas de estos símbolos agrupan un amplio repertorio desde sencillas estructuras geométricas hasta conformaciones de compleja base interpretativa ${ }^{27}$. En este sentido, se aprecia una proyección continuista entre la simbología alquímica y la obra de Emma Kunz.

También, en palabras de Harald Szeemann, exploró "las grandes polaridades: Macrocosmos y Microcosmos, Dios y hombre, salud y enfermedad, y así intervenir entre ellos para hilar redes de malla fina, una red de conocimiento y corazonada" 28 . De nuevo, esta perspectiva la acercaría al pensamiento paracélsico:

"En realidad, si el hombre no hubiera sido constituido dentro del orbe y de todas sus partes, el pequeño mundo del Microcosmos no hubiera podido existir ni hubiera sido capaz de recibir todo lo que el Gran Mundo produce. Por eso resulta que todo cuanto el hombre come o consume es verdaderamente una parte de sí mismo y que, habiendo nacido del Macrocosmos y siendo en cierto modo semejante a él, forma parte también del Gran Mundo. No es cierto pues que el hombre haya sido hecho de la nada; por el contrario, ha sido fabricado (fabrefactus) del Gran Mundo, razón por la cual se le encuentra en él.

Esa es la razón por la que, existiendo entre ambos un nexo (nexus) de dependencia tal como el de un hijo a un padre, sea natural que nadie pueda socorrer más rápidamente al cuerpo humano que aquel que es como su propio padre"29.

26 SZEEMANN, H.: "More than Art...", op. cit., p. 58. De acuerdo con la sección de Secretaría del Emma Kunz Zentrum, la única referencia con Rudolf Steiner era simplemente que eran contemporáneos. SEKRETARIAT: $o$ p. cit.

27 Resulta de gran interés al respecto la consulta de GUILEY, R. E.: The Encyclopedia of Magic and Al chemy. New York, Facts on File an imprint of Infobase Publishing, 2006

28 SZEEMANN, H.: "More than Art..., op. cit., p. 55.

29 PARACELSO: op. cit., p. 215 


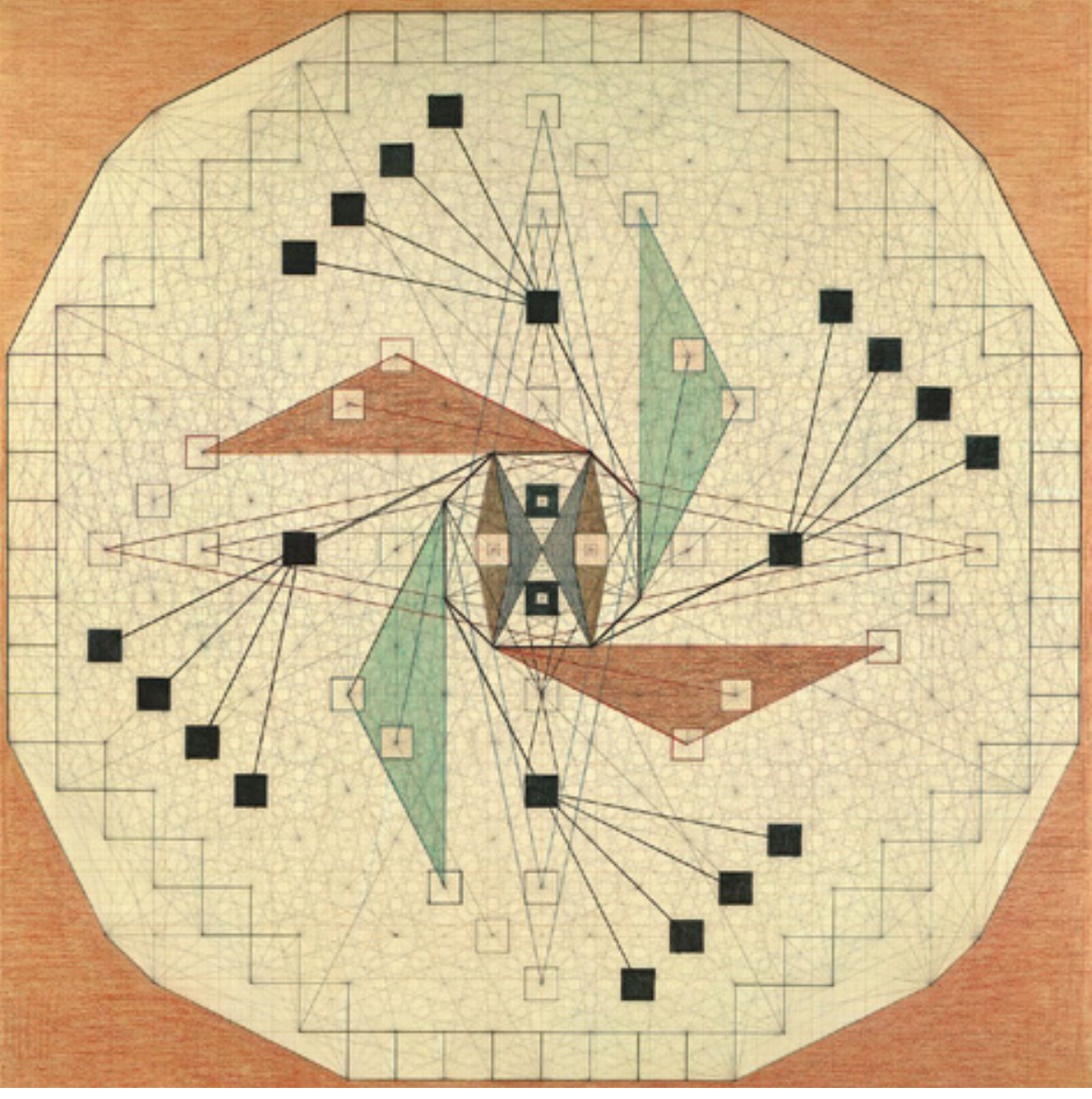

Fig. 2: Dibujo n. 004. Lápiz, lapiceros de color, óleo, pastel sobre papel cuadriculado. Sin fecha. $104 \mathrm{~cm}$ x $104 \mathrm{~cm}$. Emma Kunz Zentrun

El conocimiento de esta codificación numérica de los distintos patrones energéticos le posibilitaba entablar proyecciones simbólicas mediante el diseño de estructuras formales. Estos números aparecen en redes armónicas, en combinaciones fragmentarias y proporcionadas sobre un eje simple o completamente asimétricas. Igualmente, los números

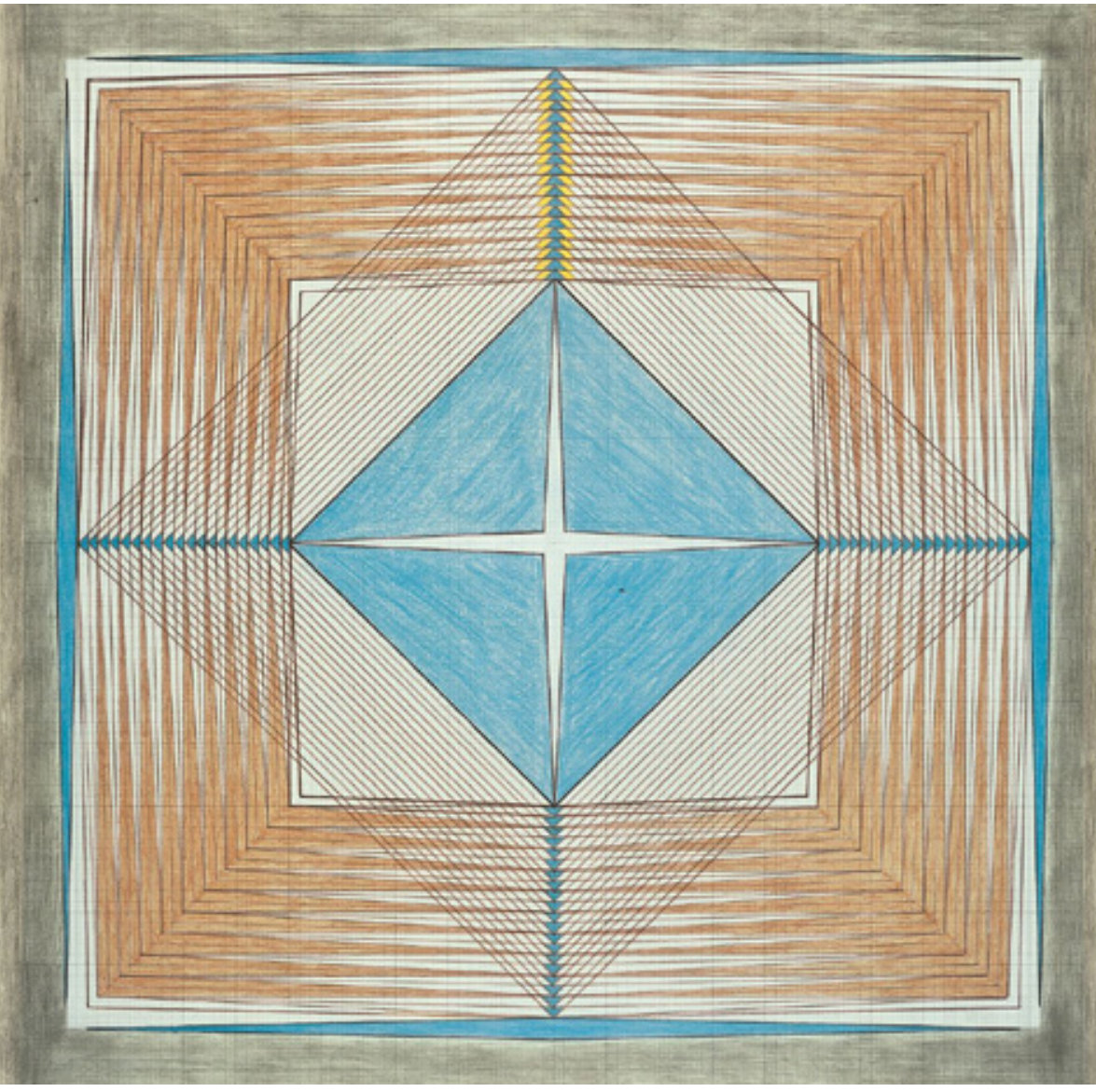

Fig. 3: Dibujo n. 005. Lápiz, lapiceros de color, óleo, pastel sobre papel cuadriculado. Sin fecha. 106 x $106 \mathrm{~cm}$ Emma Kunz Zentrum

se pueden encontrar como conjuntos de rayos, en composiciones de figuras geométricas, cuadrados, triángulos, octógonos, rombos, así como en cruces verticales y diagonales. En este sentido, la conformación de estos complejos gráficos dificulta enormemente su interpretación, lo que podría llevar a generar relatos erróneos. 
Uno de los números fundamentales en su trabajo residía en el 3, claramente alusivo a la Trinidad, como requisito previo de su trabajo. La simbología de este dígito resulta esencial en todas las religiones y filosofías herméticas. También, el número 4 es otro de sus referentes cruciales, símbolo de la naturaleza y la materia, los cuatro puntos del mundo en el ciclo del año y las cuatro fases lunares. Con el griego Empédocles vinieron los Cuatro Elementos agregados. En la exégesis cristiana, se aplica a las cuatro naturalezas del cuerpo humano: seco, húmedo, frío y cálido. De hecho, este número representa para Emma Kunz el portador de las cuatro fuerzas representativas de la naturaleza: mineral, vegetal, animal y humano. En otro apartado, tanto el tres como el cuatro son dígitos básicos en las fuerzas de impacto en las moléculas de ADN de nuestras células, por ejemplo, cada aminoácido debe estar especificado por al menos 3 nucleótidos, siguiendo la analogía del código, lo que proporcionaría 43 o 64 combinaciones posibles, como códigos genéticos de las moléculas de $\mathrm{ADN}$. De ahí que estos anteriores números se muestren como base elemental en la elaboración de múltiples trabajos, caso del dibujo 086 (fig. 4), donde se sitúa un triángulo en la parte superior, es decir, una trinidad que interactúa tanto con el resto de estructuras lineales como con las cabezas de las siluetas del hombre y la mujer. Son numerosas las composiciones que se establecen en base al tres y al cuatro, caso del número 025 .

También, se debe anotar su gran devoción por el santo suizo Nicholas de Flue (1417-1487) quien entre sus numerosas visiones, destacó especialmente en un formato logográfico reducido, una rueda mística. Nicolás describió en su visión la aparición del Santo Rostro en el centro de un círculo con las puntas de tres espadas tocando los dos ojos y la boca mientras que otras tres se irradiaban hacia afuera. En esta estructura, el movimiento sale del centro y vuelve al mismo punto. La imagen de la rueda se hace pública en 1487 por un peregrino desconocido con una explicación del Hermano Klaus: "Ese es mi libro en el que aprendo y busco el arte de esta enseñanza" ${ }^{30}$. Esta representación muestra un parentesco con las ruedas solares de la Edad del Bronce (que a menudo se encuentran en Suiza) y los diagramas cristianos, que se remontan al inicio de esta religión y a los que daría tanto valor espiritual el propio San Agustín. Incluso, Carl Gustav Jung hizo un estudio de las visiones del santo helvético, observando que sus sueños y percepciones estaban en gran parte sin adulterar por el aprendizaje formal que no sea el conocimiento catequético rudimentario de la época, representando dichas experiencias visualizadas los arquetipos universales ${ }^{31}$.

30 Para obtener más información al respecto, remitirse a las siguientes páginas web: http://www.bruderklaus.ch/ y https://www.nvf.ch/ (Consultado el 24/03/2020). En esta primera página se puede revisar una versión ilustrada de esta rueda mística, que se realiza durante la vida del ermitaño, así como bibliografía relevante sobre esta figura histórica.

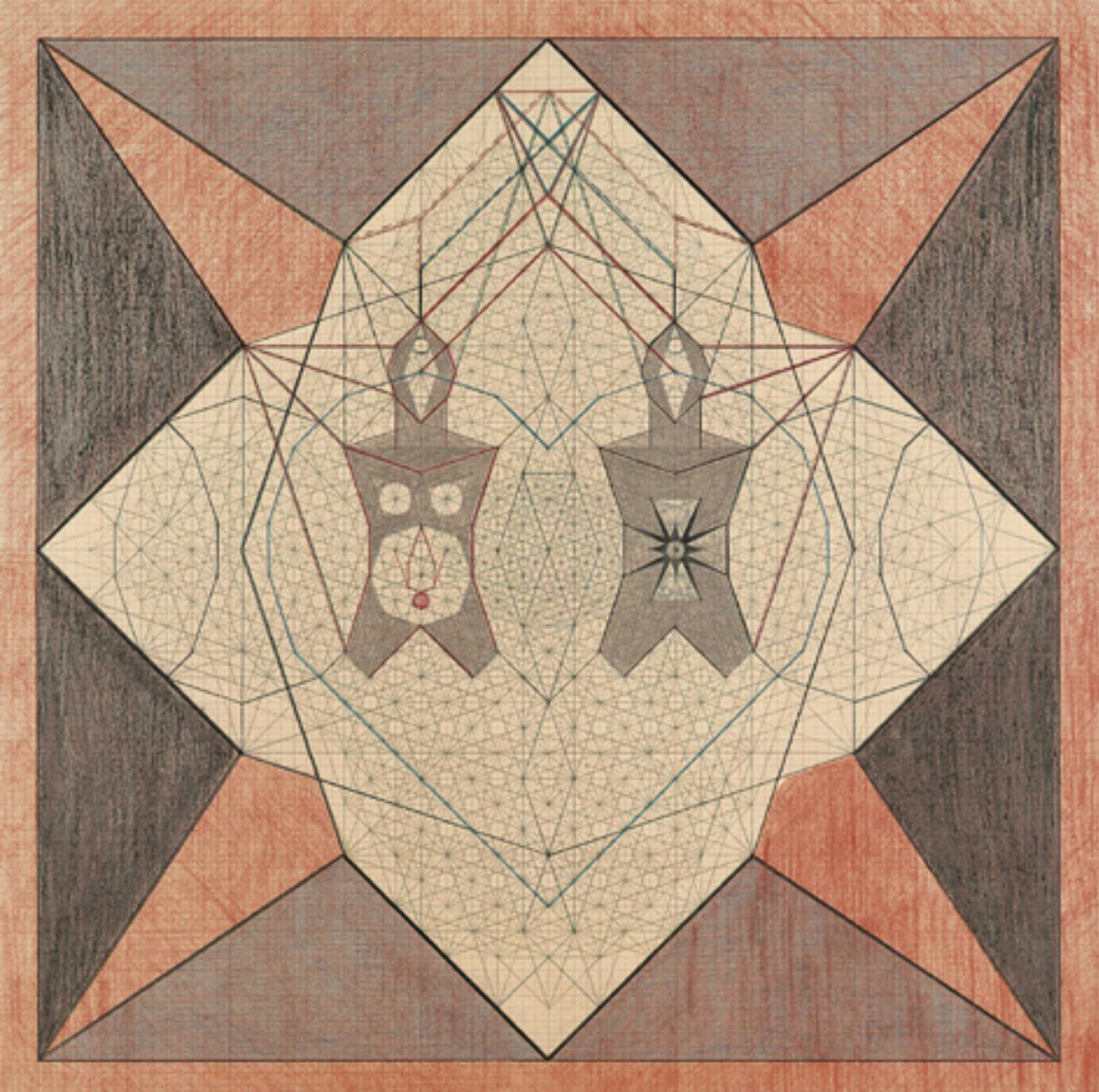

Fig. 4: Dibujo n. 086. Lápiz, lapiceros de color, óleo, pastel sobre papel cuadriculado. Sin fecha. $90 \mathrm{~cm}$ x $90 \mathrm{~cm}$. Emma Kunz Zentrum

31 Para recabar más información sobre el tema, remitirse a JUNG, C. G.: The Collected Works of the Archetypes and the Collective Unconscious. Volume 9, second edition. Princeton, New Jersey, Princeton University Press, 1969, pp. 8-65 


\section{PRÁCTICA ARTÍsTICA Y METOdología RAdiestésica}

Se cree que desde joven ya manejaba el péndulo, además de combinarlo con el dibujo a lápiz en sus incursiones a través de la naturaleza. Pero, será en 1910, cuando comience a desarrollar de una manera más continuada esta práctica intuitiva mediante el uso de péndulo $^{32}$ (fig. 5), produciendo sus primeros dibujos en cuadernos para ejercicios escolares que solía llevar consigo. En un comienzo, el uso rabdomante era empleado para verificar la certeza de sus vislumbres clarividentes, realizar mediciones energéticas, encontrar aguas subterráneas y espacios curativos, actividades habituales en los practicantes de la radiestesia. Tal y como comenta Annelise Zwez: "algunas veces se quitaba los zapatos cuando estaba cerca de grandes árboles, con el propósito de sentir las corrientes de energía a través de sus pies desnudos"33. En cualquier caso, todo era comprobado y verificado mediante el uso del péndulo, para ser posteriormente anotado y documentado.

Una vez que decidió más adelante proceder con la elaboración de sus gráficos de gran formato, el proceso se articulaba mediante la proyección de una pregunta, relacionada con una cuestión terapéutica, social o en base a cualquier referente vital o espiritual, con el propósito de diseñar una composición abstracta a modo de respuesta ante la correspondiente indagación. En este sentido, su aportación metodológica se sustenta en la ejecución de un diseño estético mediante un procedimiento de práctica radiestésica ${ }^{34}$. Por ejemplo, este planteamiento direccional es explicado de la siguiente manera por diferentes autores: "La estructura básica, dibujada mediante la plomada sobre el lienzo, estaba completamente determinada, por milímetro, con la ayuda de su péndulo. Percibía los números y los dibujos gracias a su mediumnidad, y luego eran validados y especificados con la ayuda del péndulo; es esta alternancia la que permitía la actividad creativa de Emma. Ella capturaba las fuerzas de la naturaleza que forman la base de las matemáticas en el universo" 35 .

Ante la pregunta realizada mentalmente, ella mantenía el péndulo en su mano derecha por encima del papel. Los movimientos del péndulo primero indicaban la distribución de los puntos fundamentales, que ella debía marcar en un papel cuadriculado. Como bien afirma

32 SEKRETARIAT: op, cit.

3 ZWEZ, A.: op. cit., p. 92

34 KLINGHAMMER, A.: "Kosmische Kunst. Die Künstlerinund Heilerin Emma Kunz und die Sphären harmonie". Astrologie Heute, 157 (2012), 38-41, p. 39.

35 POLIZZI, P. \& POLIZZI, M.: Se transformer par l'Ethérapie. Paris, Etherapie, 2017, p. 114

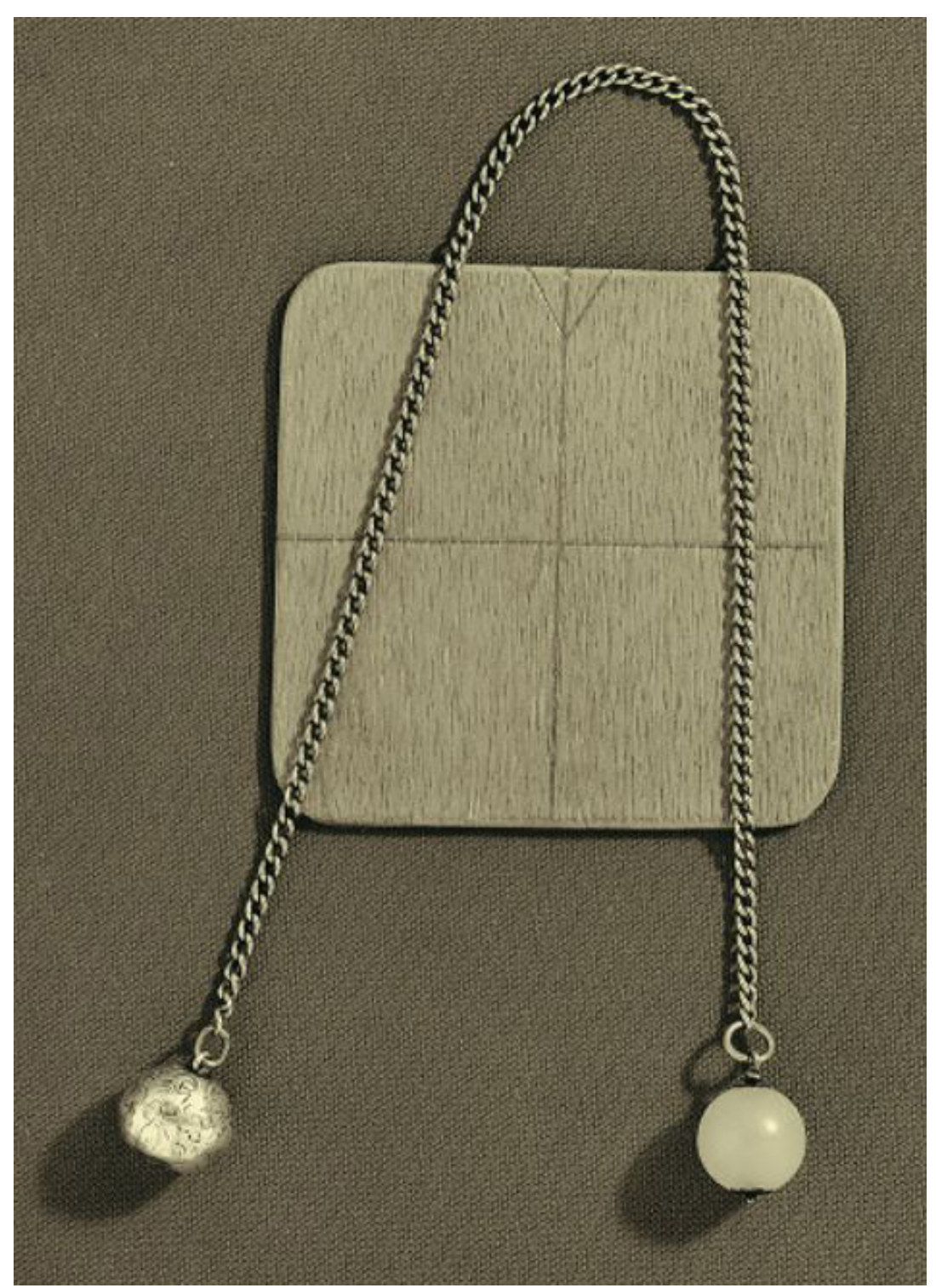

Fig. 5: Péndulo de Emma Kunz. Emma Kunz Zentrum 
Anton C. Meier: “Todavía puedo rescatar mi sentido de sorpresa por la velocidad con la que ella localizaba los puntos clave con la ayuda de su péndulo y después dibujaba las líneas conectivas. No había conteo, ni cálculo, ni medición, ni construcción geométrica: sólo la ejecución de una inspiración directa" ${ }^{36}$

De este modo, con la mitad de su pulgar imprime una marca en la hoja, generando sistema ordenados con puntos clave. Esto le da la posibilidad de producir un patrón nuevo en base a su intuición ${ }^{37}$; un procedimiento en el que Beuys incidirá al comentar que el hecho de dibujar con el brazo extendido era en sí una proyección del pensamiento, con el objetivo de demandar las fuerzas de la intuición. Para el artista alemán:

"La idea de intuición, imaginación, inspiración... se relaciona con el principio de un mundo invisible. Cuando llamo a estos dibujos El bloque secreto, trato de enfatizar esta parte de la realidad como la más importante, ya que la existencia espiritual está en primer lugar... Encuentro que si solo nos enfrentamos con esta parte difícil del mundo, esta parte ya hech del mundo, no estamos... relacionándonos con la idea general de la realidad... La misión del arte es hacer visible toda la realidad"38.

Emma Kunz anota en sus escritos la relevancia que tiene la intersección de estos puntos o nodos, siendo generados de manera intuitiva con el fin de producir efectos concretos y de este modo proyectar la energía de la conciencia superior en una materialización física, por este mismo motivo, procedió a diseñar nuevos símbolos y estructuras que estaban sujetas a un acto de contemplación más que de observación. Como afirma la artista: "El mundo es un preludio de nuestra vida espiritual. Intentemos tejer el sonido más luminoso en el tono de la imagen" 39

Posteriormente, en base a dichos puntos y siempre empleando el péndulo, como elemento orientador, establecía las líneas principales y secundarias del gráfico mediante un lápiz. Más adelante, se aplicaba el cromatismo en diferentes secciones con lapiceros de color

36 MEIER, A. C.: op. cit., p. 28.

37 Desde la sección de Secretaría del Emma Kunz Zentrum se nos subraya que su trabajo se basa en cuestiones de aplicación intuitiva y no de mediumnidad. SEKRETARIAT: op. cit.

38 Joseph Beuys, en WALTERS, V.: Ioseph Beuvs and the Celtic Wor(l)d: A Language of Healing. Münster Lit Verlag, 2012, p. 198

39 Emma Kunz, en ANDERHUB, W. \& ROTH, H. P.: Crop Circles. Exploring the Designs \& Mysteries. New York, Lark Books, 2002, p. 130. ceras, e incluso óleo y pastel, dependiendo de las necesidades de proyección energética. Sabía exactamente que colores y la intensidad de raya que había que administrar, ya que cada línea desplegada (delgada, media o gruesa), así como cada color y forma, tenían un sentido preciso, de acuerdo a la información que le aportaba el péndulo y su propia intuición. Los colores básicos de muchos de sus trabajos recaban en el rojo, azul y amarillo, caso de los números 003 y 508.

Todos los trabajos se realizaban de principio a fin, sin interrupciones, siendo procesos muy largos en su materialización. La gran mayoría de los dibujos son de gran formato, habitualmente realizados durante la noche, ya que es su momento de mayor inspiración y conexión intuitiva, aunque algunos de ellos conllevaban una ejecución de veinticuatro horas. Heiny Widmer, que organizó la primera exposición de su obra en el Kunsthaus de Aargau (Suiza), en 1973, 10 años después de su muerte, describe cómo solía realizar sus trabajos:

"Emma Kunz usaba el péndulo como un estímulo de la misma manera en que otros artistas usan otras mediciones para crear condiciones favorables en su trabajo. A menudo decía que de repente aparecería en su imaginación un sistema ordenado de puntos. Los escribía e interpretaba de inmediato como un patrón básico de una nueva figura. Luego completaba el patrón básico, lo enriquecía, consultando al péndulo y de acuerdo a su visión interna. A menudo parecía como si la imagen se hubiese completado fuera de su conciencia, como si sus manos hubieran sido dirigidas. Cuando se terminaba un trabajo, la pintora se situaba frente a lo que ella había creado, con gran asombro, retornando de unas profundidades distantes" ${ }^{\prime 40}$

Estos trabajos se podrían entender como una especie de hologramas, ya que nos encontramos ante diferentes planos y estructuras que se solapan y se van superponiendo. A pesar de que el espectador sólo pueda observar una proyección bidimensional, estaríamos ante un auténtico entramado estratigráfico. Dichos dibujos eran representaciones de "un sistema específico de ley"41, que de acuerdo a su propia intuición debía producir sanación y fomentar espacios de protección. Tal y como se confirma desde la sección de Secretarí del Emma Kunz Zentrum: "los pacientes tenían que contemplarlos (durante un tiempo dilatado), situarlos en los dormitorios y meditar sobre ellos (...)"42.

40 Heiny Widmer, en Idem, p. 131

41 ZEGHER, C. de: "Abstract", op.cit., p. 30

42 SEKRETARIAT: $o p$. $c i$ 
Dependiendo del tipo de investigación, realizaba tres categorías de dibujos: balanceo figurativo, simbólico y energético. En el primer caso, siempre encontramos figuras en las composiciones estructurales, a menudo inscritas en redes rómbicas (ver, por ejemplo, los dibujos número 12, 139 y 552) (figs. 6, 7 y 8). En cualquier caso, la mayoría de sus trabajos se relacionan con las dos últimas modalidades, resultando en propuestas abstractogeométricas. Indiferentemente, de su resultado final, la artista no proporcionó explicaciones escritas para que no fueran malentendidas y distorsionadas. Por este motivo, impidió que su propio discurso fuera anotado o grabado magnetofónicamente.

Solía emplear un péndulo con cadena y bola de plata y en el otro extremo un remate de jade. Como instrumento adicional de trabajo, podía emplear una pequeña tabla cuadrada de madera directamente sobre el papel, que funcionaba como una brújula virtual. De esta manera, era capaz de representar cualquier tipo de diagrama y gráfico. Harald Szeemann explica su procedimiento metodológico en el siguiente comentario:

"Usando su péndulo, y el tablero en el que ella había marcado una cruz y el signo del Hombre en la Luz (transcendiendo la cruz), ella primero marcaba las líneas básicas direccionales: diagonales, resistencias de los elementos, apertura a los elementos, y la línea horizontal de la fuerza que corta a través de la intención divina. En tales momentos, su conocimiento e intuición sobre lo que se le estaba dictando coincidían perfectamente" ${ }^{\text {"33. }}$.

Siempre trabajaba en una pequeña mesa con un gran tablero de dibujo, junto con papel cuadriculado, un lápiz para marcar los puntos y un simple riel de madera. Una vez finalizado el proceso creativo, la manera de presentar sus trabajos siempre era en posición horizontal sobre plintos, aunque luego posteriormente serían todos colgados sobre paredes, a menudo, de diez a veinte hojas una encima de la otra

Otro artista que también sintió interés por la aplicación pendular en la configuración creativa fue Paul Klee, quien anotaría lo siguiente: "En el balanceo del péndulo aparecen nuevas fuerzas, que bajo ciertas circunstancias destruyen la dominación de la gravedad. Entonces, lo estático se suspende y la dinámica toma su lugar"34. Aunque este último fue consciente de las nuevas posibilidades del uso pendular, sería Emma Kunz la que

43 Harald Szeemann, en CHON, D. \& PHILIPS, G. \& RIGOLO, P. (eds.): op. cit. p. 206

44 Paul Klee, en SPILLER, J. (ed.): Paul Klee: Notebooks. Volume 1: The thinking eye. London, Lund Humphries, 1973, p. 386.

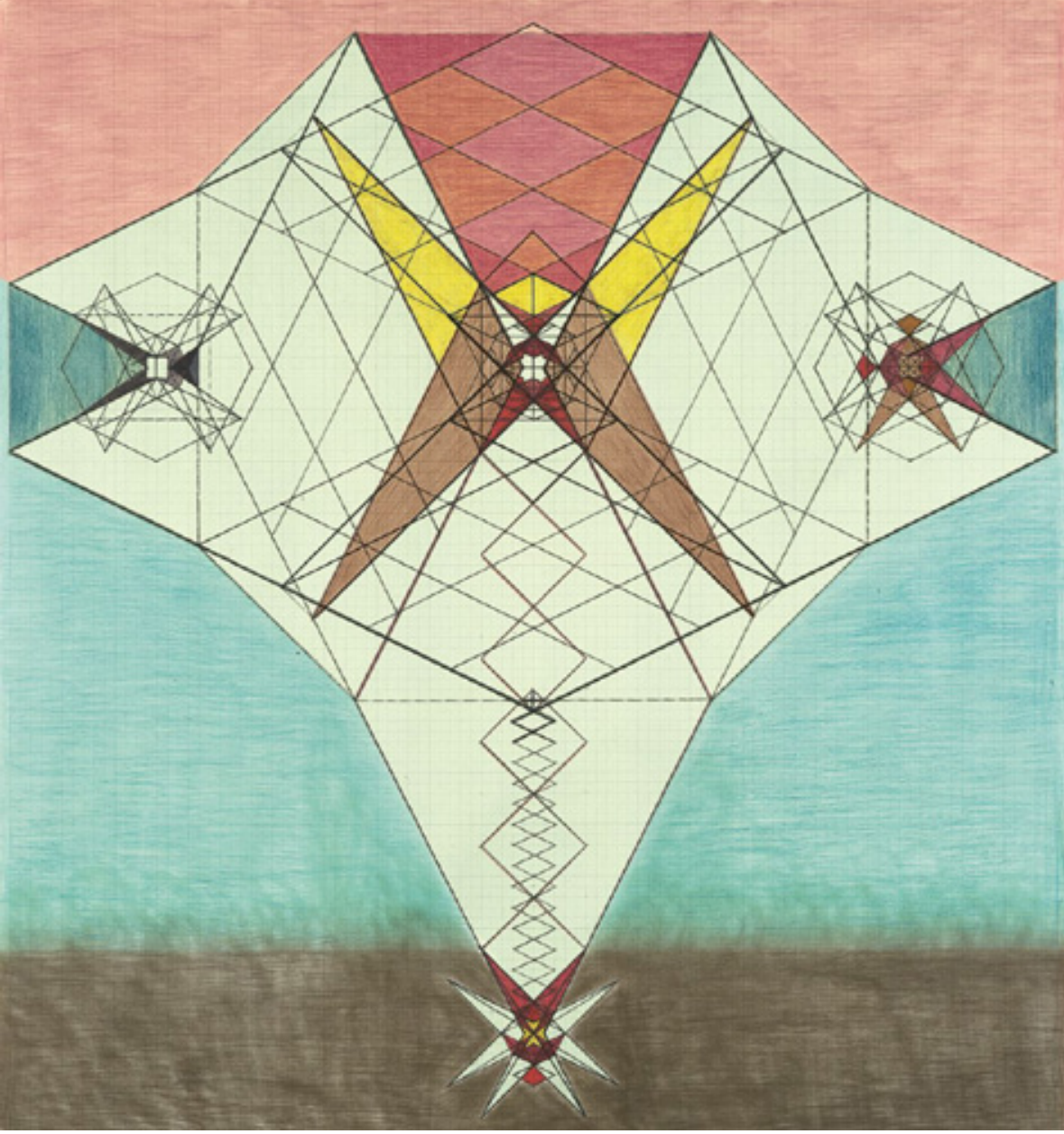

Fig. 6: Dibujo n. 012. Lápiz, lapiceros de color, óleo, pastel sobre papel cuadriculado. Sin fecha. 110 x $105 \mathrm{~cm}$. Emma Kunz Zentrum 


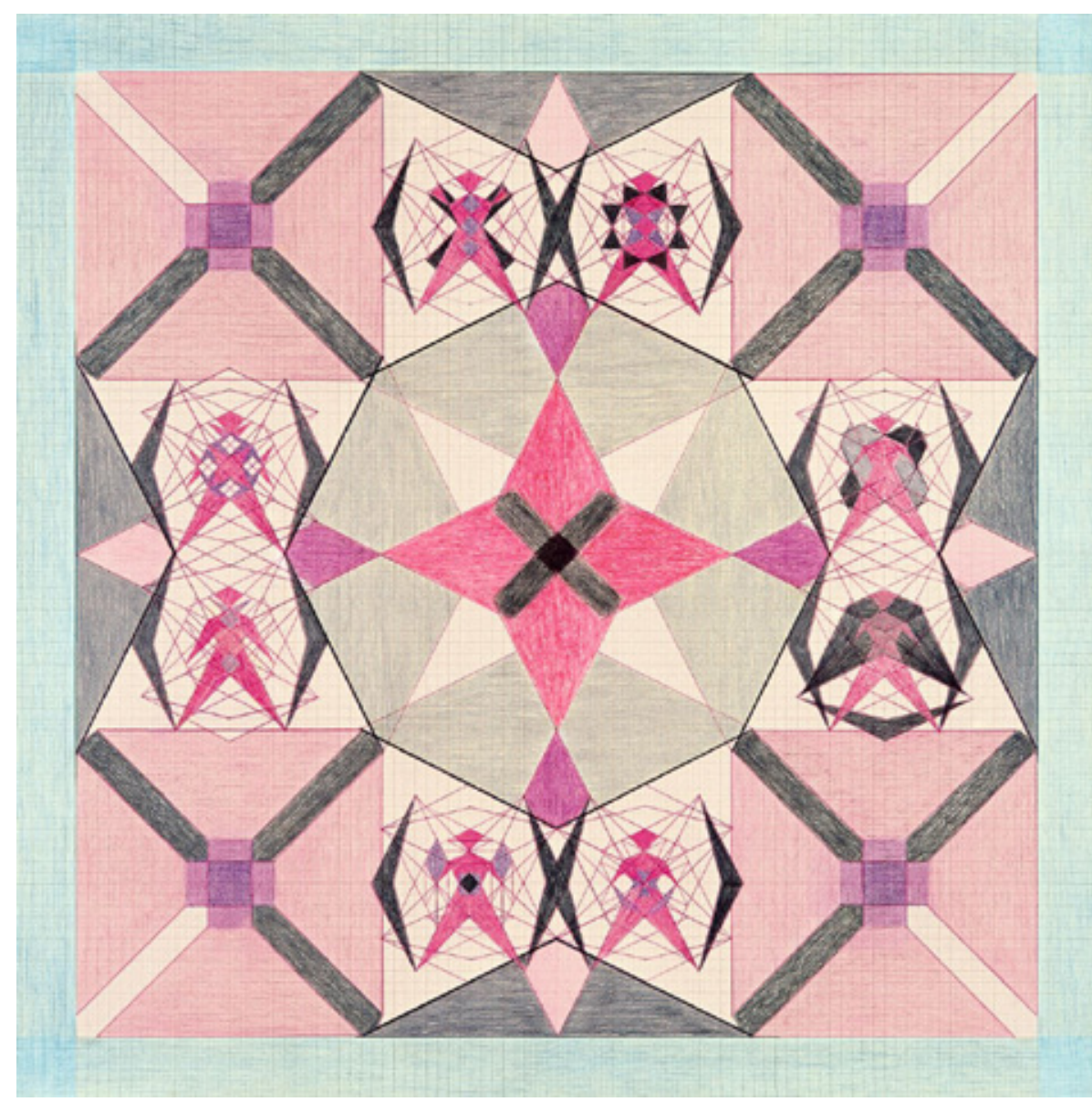

Fig. 7: Dibujo n. 139. Lápiz, lapiceros de color, óleo, pastel sobre papel cuadriculado. Sin fecha. 100 x $100 \mathrm{~cm}$. Emma Kunz Zentrum

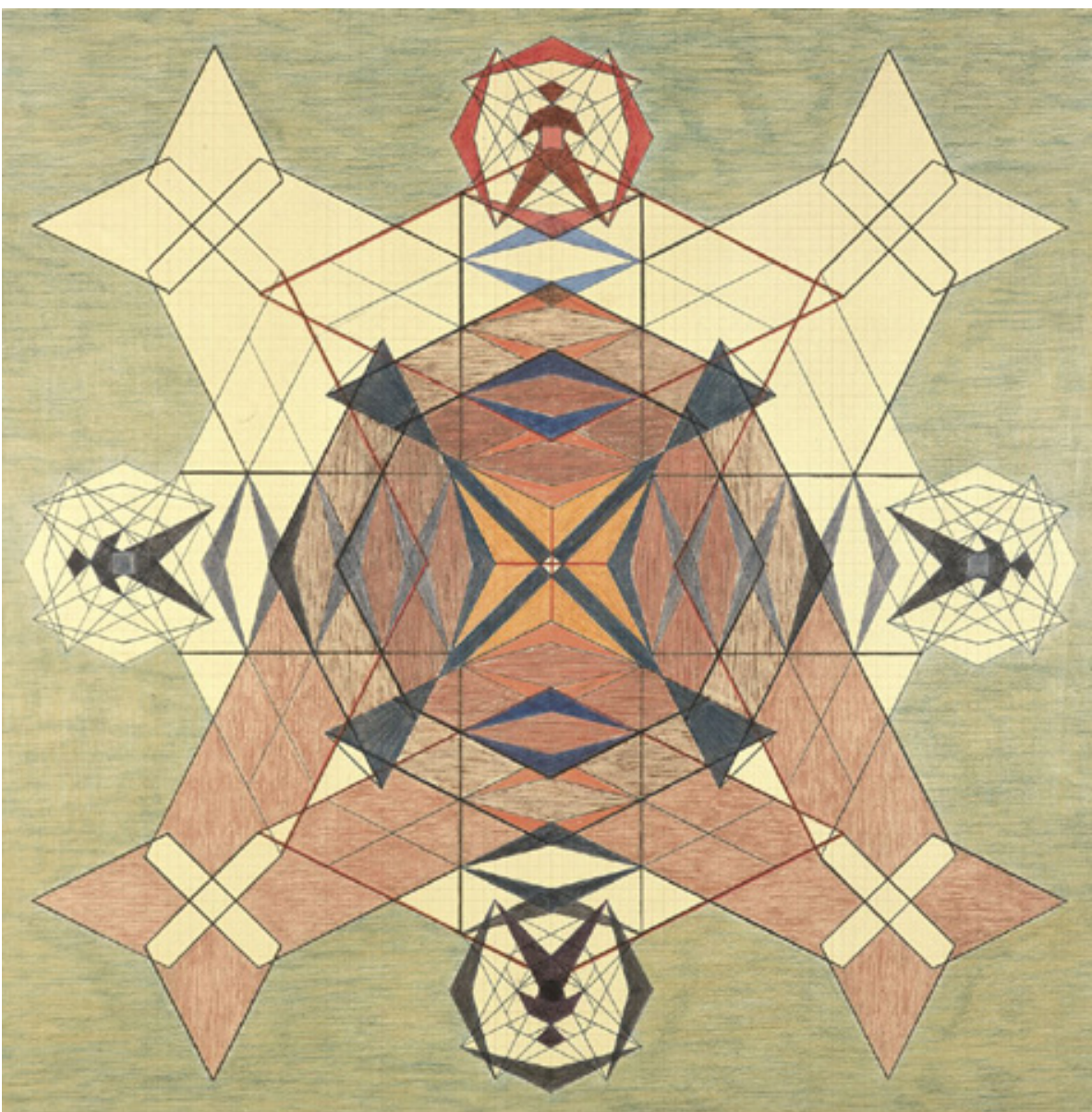

Fig. 8: Dibujo n. 552. Lápiz, lapiceros de color, óleo, pastel sobre papel cuadriculado. Sin fecha. 100 x $97 \mathrm{~cm}$ Emma Kunz Zentrum 
realmente materializaría unos códigos invisibles mediante esta práctica. Si el objetivo de Paul Klee era representar fuerzas cósmicas mediante el dibujo, Emma Kunz emplea el dibujo como entrada interactiva e influyente en su entorno. Esta herramienta rabdomante la posibilitaba canalizar su capacidad intuitiva y le marcaba las direcciones y trazos de las distintas estructuras que proyectaba, fomentando un tipo de composiciones que se acercaban a mandalas, yantras, dibujos hipnóticos e incluso diagramas teleinfluyentes, como los empleados por los practicantes radiestésicos. Estos gráficos y especialmente los obtenidos para fines curativos, emitían una onda de forma que afectaba al espectador que lo contemplaba; una nueva manera de entender la curación que se enmarcaba en lo que sería una nueva perspectiva de la medicina del futuro. De hecho, hoy en día numerosos terapeutas suizos siguen prescribiendo dibujos de Kunz a sus pacientes, cuestión que es explicada de la siguiente manera:

"Muchos científicos y físicos cuánticos reconocen el poder de transmisión mental en un patrón de característica geométrica simple, o como un diseño ondulado de un rastro de energía. Nuestros pensamientos tienen forma de transmisión en forma similar a la de un patrón de una ONDA de forma simple. Este tipo de transmisión puede tener un patrón geométrico y se comporta como una onda que contiene el significado completo de la intención de nuestros pensamientos en un momento dado de intensidad" ${ }^{\text {"45. }}$.

Especialmente significativo, resulta el dibujo número 168 (fig. 9), que muestra el descubrimiento del $A I O N$ A, un diagrama que representa la piedra curativa del mismo nombre, creado expresamente para ser contemplado y que pueda actuar a modo de canal transmisor de fines sanadores, tal y como es aceptado dentro del ámbito radiestésico, de acuerdo a los comentarios de Blanche Merz y su efecto de emisión curativa ${ }^{46}$.

Emma Kunz actuaba como una receptora de energía, materializándola en un complejo dibujo que era articulado por el péndulo. De hecho, creía que su conocimiento de las fuerzas y energías trascendentales le dotaban de poder para ejercer la curación, afirmando que "todo sucede de acuerdo con un sistema específico de la ley, lo que siento dentro de mí, y que nunca me permite descansar" ${ }^{\text {"47 }}$. De este modo, mediante la creación de

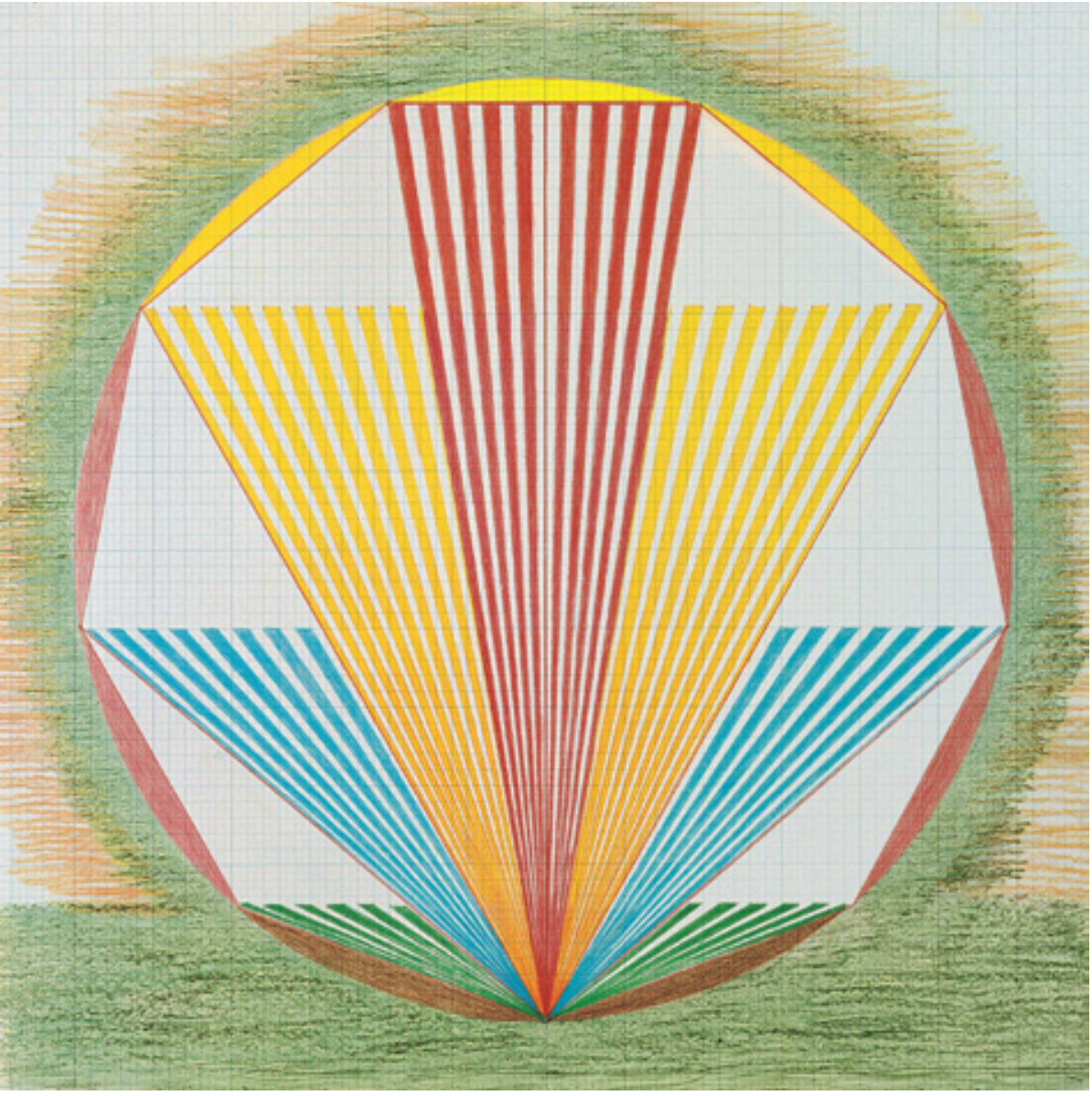

Fig. 9: Dibujo n. 168/AION A. Lapiceros de color, óleo, pastel sobre papel cuadriculado. $1942.70 \mathrm{~cm}$ x $70 \mathrm{~cm}$ Emma Kunz Zentrum 45 ZORRILLA, F.: Conociendo a Dios a Través De La Ciencia: Realidades Que Debes Saber. Bloomington,
IN., Palibrio, 2013, p. 119 .
46 MERZ, B.: "The Emma Kunz Grotto. A Place of Power", op. cit., p. 176.

47 Emma Kunz, en ZEGHER, C. de: "Abstract", op. cit., p. 30 
dichos gráficos, se buscaban tanto soluciones terapéuticas, como todo tipo de consejos y aplicaciones resolutivas ante problemas de cualquier índole. En muchos casos, de acuerdo a las necesidades del paciente, se situaban diferentes dibujos entre el enfermo y ella, lo que le facilitaba obtener intuitivamente qué diagrama podría ser el más adecuado para su terapia, una práctica que recuerda los métodos chamánicos y la elaboración de pinturas de arena de los navajos ${ }^{48}$, en definitiva, métodos de sanación basados en patrones energéticos. De acuerdo a Janis Lander: "Algunos artistas/curadores como Emma Kunz (1892-1963) usaban su arte, como una parte intrínseca de sus prácticas curativas, en la manera en que los chamanes habían utilizado tradicionalmente el arte - mapeando las estructuras energéticas del paciente y la relación del paciente con las fuerzas cósmicas"49. También, Susan T. Klein se expresa de un modo similar: "En sus dibujos, ella, en mi opinión, dibujaba su conexión con el inconsciente universal (donde todo es conocido) - desde su corazón. Su cuerpo/mente/espíritu conectaba con el cuerpo/mente/espíritu del individuo que estaba curando. Tal y como mencioné, sus dibujos son una representación de los campos de fondo energéticos" ${ }^{\prime 5}$

La aplicación de esta nueva metodología creativa para la ejecución de diagramas y gráficos basados en el uso pendular sobre papel cuadriculado de gran formato quedó sistematizada en sus libros de 1953, que en palabras de la propia artista podría ser practicada y ensayada por cualquier individuo: "Una vez que se anuncie la clave de este novedoso método de dibujo, permite a cualquier persona crear tales entidades, siempre que coincidan con el número y se sepa cómo manejarlo" ${ }^{51}$. Este tipo de práctica tan poco ortodoxa le canjeó diferentes problemas en un principio, aunque con el tiempo llegaría a convertirse en una figura respetada y reconocida en Suiza. De hecho, ya había dado testimonio de que su trabajo sería sólo entendido en el siglo XXI ${ }^{52}$.

48 TEICHER, H.: "Kaleidoscopic Visions", op. cit., p. 132

49 LANDER, J.: Spiritual Art and Art Education. New York, Routledge, 2014, p. 24

50 KLEIN, S. T.: "Emma Kunz as Healer", en ZEGHER, C. de \& TEICHER, H. (eds.): op. cit. p.141.

51 Emma Kunz, en ZWEZ, A.: op. cit., p. 91.

52 Emma Kunz, en ZEGHER, C. de: "The Inside is the Outside: The Relational as the (Feminine) Space of the Radical". Lecture given at the Conference: Women Artists at the Millennium. Princeton University. http://www.rochester.edu/in_visible_culture/Issue4-IVC/de_Zegher.html (Consultado el 24/03/2020).

\section{CONCLUSIONES}

En los últimos tiempos y gracias a la proyección de las revisiones histórico-artísticas desde el ámbito de los estudios feministas, se ha logrado exteriorizar con más visibilidad la figura de la artista suiza Emma Kunz, que desarrolló un nuevo método representativo de dibujos de compleja organización compositiva e intencionalidad curativa. Para ello, realizaba una pregunta mental relacionada con la problemática física o psicológica del paciente, y a partir de ahí diseñaba un diagrama estructurado y coloreado que pudiera servir de respuesta terapéutica a la cuestión solicitada. En conexión con la pregunta mental y la posible solución, la artista manejaba el péndulo para establecer los puntos principales de la composición, que posteriormente serían unidos conformando una compleja estructura de líneas, formas geométricas, planos y espacios coloreados.

El movimiento pendular se producía mediante la habilidad radiestésica de Emma Kunz, lo que le propiciaba establecer tanto los puntos como las líneas que se debían articular en su gráfico, así como los colores y sombreados, que debía aplicar, adquiriendo cada elemento un sentido concreto. Para la ejecución de estas proyecciones simbólicas, la creadora admitió la necesidad de dominar un conocimiento numérico, ya que en realidad sus dibujos eran patrones energéticos basados en codificaciones de números.

Sobre la base de un pensamiento holístico y una inédita aplicación metodológica se generaba un diseño estético de procedimiento radiestésico. No había cálculo, ni medición, ni previa construcción geométrica, únicamente se procedía mediante la intuición rabdomante, siendo su principal herramienta de trabajo un péndulo con cadena y bola de plata y en el otro extremo un remate de jade, para posteriormente hacer uso de los lapiceros de color, el pastel y el óleo. Estos trabajos artísticos mantienen una cercanía visual con las estructuras formales de los mandalas, yantras, dibujos hipnóticos e incluso diagramas teleinfluyentes, que se suelen utilizar por parte de los practicantes radiestésicos. A modo de hipótesis, ya que no existen datos exactos ni concretos al respecto, se supone que pudo llegar a consultar diversas fuentes de la literatura alquímica de Paracelso, tratados del pensamiento orienta y cristiano y especialmente corrientes coetáneas de las escuelas herméticas europeas, como la antroposofía de Rudolf Steiner. Para Emma Kunz, estos gráficos emitían una onda de forma que afectaba a la persona que lo contemplaba, por este motivo, sus pacientes y espectadores debían presenciar sus dibujos por periodos dilatados de tiempo, con el objetivo de que produjeran efectos concretos en relación con la problemática existente de dicho observador. En definitiva, una nueva manera de entender y proyectar la curación holística mediante soportes estéticos y artísticos. 


\section{BIBLIOGRAFÍA}

ANDERHUB, W. \& ROTH, H. P.: Crop Circles. Exploring the Designs \& Mysteries. New York, Lark Books, 2002

CHON, D. \& PHILIPS, G. \& RIGOLO, P. (eds.): Harald Szeemann: Selected Writings. Los Angeles, Getty Research Institute, 2018.

EMMA KUNZ ZENTRUM. KUNZ: “Emma Kunz. Artist, Researcher, Healer”, en: https:// www.emma-kunz.com/

HOFMANN, V.: "Superwoman Emma Kunz. Aspekte aus John Grays Buch Wir werden wie Gott sein als Basis für eine Betrachtung des Lebenswerkes von Emma Kunz”, sección 2, en: http://verahofmann.de/sandberg/CM3_writing_VH.pdf

JUNG, C. G.: The Collected Works of the Archetypes and the Collective Unconscious. Volume 9, second edition. Princeton, New Jersey, Princeton University Press, 1969.

KLEIN, S. T.: "Emma Kunz as Healer", en De ZEGHER, C. \& TEICHER, H. (eds.): $3 \times$ Abstraction. New methods of drawing. Hilma Af Klint, Emma Kunz, Agnes Martin. New York, The Drawing Center, Yale University Press, 2005, pp. 139-141.

KLINGHAMMER, A.: "Kosmische Kunst. Die Künstlerinund Heilerin Emma Kunz und die Sphären harmonie". Astrologie Heute, 157 (2012), pp. 38-41.

KRUMM, R.: Bewusst weiter gehen: Vom persönlichen zum ganzheitlichen Weltbild. Norderstedt, BoD - Books on Demand, 2018.

LANDER, J.: Spiritual Art and Art Education. New York, Routledge, 2014.

MEIER, A. C.: "Emma Kunz. Life and Work", en VV.AA.: Emma Kunz: Artist, Researcher, Natural Healer. Würenlos, Emma Kunz Zentrum, 1998, pp. 19-54.

MERZ, B.: "The Emma Kunz Grotto. A Place of Power", en VV.AA.: Emma Kunz: Artist, Researcher, Natural Healer. Würenlos, Emma Kunz Zentrum, 1998, pp. 169-207.

MOREL, H. V.: Radiestesia. Cuestionario integral. Buenos Aires, Kier Editorial, 2005.
PARACELSO: Obras Completas (Opera Omnia). Sevilla, Renacimiento, 1992.

POLIZZI, P. \& POLIZZI M.: Se transformer par l'Ethérapie. Paris, Etherapie, 2017.

SPILLER, J. (ed.): Paul Klee: Notebooks. Volume 1: The thinking eye. London, Lund Humphries, 1973.

SZEEMANN, H.: "More than Art: Tiend into Primal Mud and Mystic Light", en VV.AA.: Emma Kunz: Artist, Researcher, Natural Healer. Würenlos, Emma Kunz Zentrum, 1998, pp. 55-90.

TEICHER, H.: "Kaleidoscopic Visions", en De ZEGHER, C. \& TEICHER, H. (eds.): $3 x$ Abstraction. New methods of drawing. Hilma Af Klint, Emma Kunz, Agnes Martin. New York, The Drawing Center, Yale University Press, 2005, pp. 127-137.

WALTERS, V.: Joseph Beuys and the Celtic Wor(l)d: A Language of Healing. Münster, Lit Verlag, 2012.

ZEGHER, C. de: "The Inside is the Outside: The Relational as the (Feminine) Space of the Radical". Lecture given at the Conference: Women Artists at the Millennium. Princeton University, en: http://www.rochester.edu/in_visible_culture/Issue4-IVC/de_Zegher.html

ZEGHER, C. de: "Abstract", en De ZEGHER, C. \& TEICHER, H. (eds.): $3 x$ Abstraction. New methods of drawing. Hilma Af Klint, Emma Kunz, Agnes Martin. New York, The Drawing Center, Yale University Press, 2005, pp. 23-40.

ZORRILlA, F: Conociendo a Dios a Través De La Ciencia: Realidades Que Debes Saber. Bloomington, IN., Palibrio, 2013.

ZWEZ, A.: “...Provided They Know How to Handle Numbers”, en VV.AA.: Emma Kunz: Artist, Researcher, Natural Healer, Würenlos, Emma Kunz Zentrum, 1998, pp. 91-118. 